\title{
AMOR E PAIXÃO NOS BASTIDORES DE UMA MISSÃO RELIGIOSA CATÓLICA NO SERTÃO DO EXTREMO NORTE DE GOIÁS (ATUAL NORTE TOCANTINENSE): QUINTO TONINI E TERESINHA FOLI
EM SEUS RELATOS DE MEMÓRIA.
}

Rayllin Barros da Silva Licenciado em História e Especialista em Ensino de História pela Universidade Federal de Tocantins. Mestre em História pela Universidade Federal de Goiás. Docente SEDUC/TO e IFTO Campus Araguaína.

rayllinbarros0908@gmail.com

resumo: Este estudo é resultado de uma pesquisa bibliográfica e seu objetivo foi buscar desvelar uma paixão entre dois missionários católicos orionitas: Teresinha Foli e Quinto Tonini, religiosos que se estabeleceram no antigo extremo norte de goiano - atual norte tocantinense - na metade do século XX, durante o processo que resultou na estruturação do catolicismo na região. Ao analisar as memórias de Teresinha, será possível constatar que os dois alimentaram um amor até o fim de suas vidas, sentimento que fez parte dos bastidores da missão e influenciou os caminhos da mesma no contexto analisado. A fonte utilizada foi relato de memória: livro já publicado. A metodologia consistiu na análise dessa fonte buscando extrair o que ela por vezes pretendeu omitir. Utilizamos como orientação metodológica e teórica, referenciais que se inserem no âmbito dos estudos autobiográficos.

Palauras-chave: Paixão, Orionitas, Goiás. abstract: This study is a result of a bibliographical research the aim is to look for unveil the passion between two Catholics missionaries "orionitas": Teresinha Foli and Quinto Tonino religious that settled in the ancient far north of Goiás state currently north of Tocantins state - in the half of the $X X$ century during the process that result in the structuring of the Catholicism in the region. When analyzing the memories of Teresinha it will be possible determine that the both nurtured the love until the end of their lives, sentiment that made part of the backstage of the mission and influenced the paths of it in the analysed context. The source utilized was secondary: report of memory: written book and already published. The methodology consisted in the analysis of this source looking for extract what she in times intended to omit. For this analytical work we utilized as methodological and theoretical orientation, references that insert in the field of self biography studies.

Key-words: Passion, Orionitas, Goiás. 


\section{introdução}

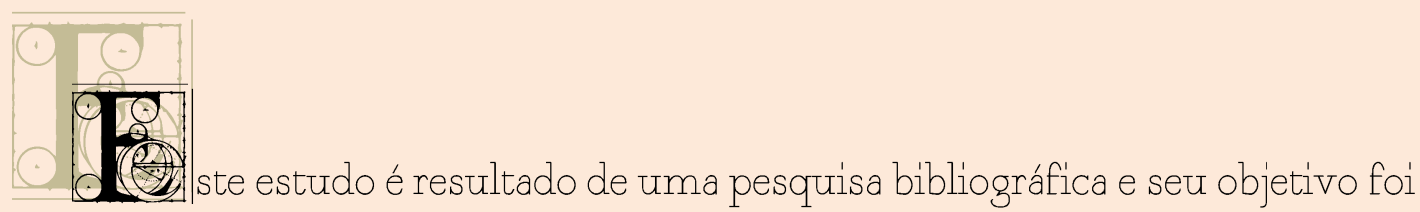
buscar desvelar uma paixão entre dois missionários católicos orionitas: Teresinha Foli e Quinto Tonini, religiosos que se estabeleceram no antigo extremo norte de goiano - atual norte tocantinense - na metade do século XX, durante o processo que resultou na estruturação do catolicismo na região. Ao analisar as memórias de Teresinha, será possível constatar que os dois alimentaram um amor até o fím de suas vidas, sentimento que fez parte dos bastidores da missão e influenciou os caminhos da mesma no contexto analisado. A fonte utilizada foi secundária, relato de memória: livro escrito já publicado. A metodologia consistiu na análise dessa fonte buscando extrair o que ela por vezes pretendeu omitir. Para esse trabalho analítico, utilizamos como orientação metodológica e teórica, referenciais que se inserem no âmbito dos estudos autobiográficos

Os missionários orionitas fazem parte de uma congregação religiosa pertencente à Igreja Católica Apostólica Romana. Essa congregação foi fundada no início do século XX - 1903 - na cidade de Tortona, Itália. O Fundador da congregação foì um sacerdote católico: Dom Luis Orione, também de nacionalidade italiana. Os missionários orionitas, seguidores de Dom Orione como é popularmente conhecido, são homens (padres e irmãos) e mulheres (freiras), que logo se espalharam pelo mundo, sobretudo depois da primeira guerra, "abraçados" por um ideário de vida, de serviço à Igreja e de assistência aos mais pobres. ${ }^{1}$

nome canônico da congregação é Pequena Obra da Divina Providência, também chamados de Filhos da Divina Providência. Sobre essa congregação católica, pode-se dizer que é considerada uma das mais novas dentro da estrutura da Igreja, mais nova é claro, se comparada com as principais congregações ou ordens católicas cuja fundação, no caso de algumas, remonta há séculos. Os orionitas estão presentes em quase todos os continentes, com uma atuação mais destacada na América Latina e Europa.

1 PATTARELLO, Giovani. Perfil de Dom Orione. São Paulo: S/Editora, 1985. 
No Brasil, os primeiros missionários orionitas que se estabeleceram na região do antigo extremo norte goiano, atualmente norte tocantinense, em fevereiro de 1952, pode-se dizer que não foram muitos em quantidade significativa. Dentre eles e que são objeto deste estudo estão Terezinha Foli e Quinto Tonini. Mas por que esses doís missionários são privilegiados neste estudo? Por que no contexto da missão surgiu um amor entre esses dois principais orionitas. Essa é a questão que perseguiremos no transcorrer deste estudo como a seguir.

\section{"ele tinha alquma coisa que me chamava atenção": terezinha foli e os indícios de uma paixão.}

Ao longo da pesquisa ${ }^{2}$ que resultou na produção deste estudo, ao analisar as narrativas escritas de memória dos missionários, pensando e repensando diálogos que travamos com alguns personagens que os conheceram de perto, deparamos com a figura que, nos bastidores da missão orionita atuou e com destaque: Teresinha de Jesus Nóbrega Foli, freira orionita, depois desligada da congregação. Essa freira alimentou um verdadeiro sentimento amoroso por Quinto Tonini, ao que parece, correspondeu ao sentimento dela. Vale observar que não é incomum surgir sentimentos amorosos entre pessoas que possuem alguma ligação religiosa e, paixões entre religiosos não é um fenômeno estranho na história do catolicismo. ${ }^{3}$

\footnotetext{
2 Pesquisa com apoio do CNPq - Conselho Nacional de Desenvolvimento Científico e Tecnológico.

3 Um dos casos mais famosos do ocidente se refere ao romance entre Pedro Abelardo e Heloísa de Paráclito. O relacionamento entre os dois se deu na França do século XII. Abelardo era considerado um brilhante teólogo e professor universitário, ligado à Igreja Católica. Heloísa era estudiosa de grego, latim e hebraico, reconhecida por sua reputação erudita. Os dois se conheceram quando ela se tornou aluna dele. Se apaixonaram e começaram a se relacionar em segredo, vindo a ter um filho. Tanto o relacionamento amoroso entre eles como o filho do casal foram escondidos por medo que aquela história prejudicasse a carreira acadêmica de Abelardo. A Igreja Católica na época detinha o monopólio da educação e costumava punir de forma severa professores que se relacionasse com suas alunas. A história depois veio à tona e após pressões da Igreja, o tio de Heloísa que havia confiado a educação da jovem aos cuidados de Abelardo, resolveu castrá-lo. A partir daí, Abelardo seguiu a vida religiosa tornando-se monge católico e Heloísa se tornou freira. Mesmo depois de seguirem a vida religiosa, já separados, os dois continuaram se correspondendo até o resto de suas vidas, um amor platônico. Essas cartas são reconhecidas também como uma "troca" intelectual entre os dois, além de uma busca espiritual. Essa alusão que fazemos da história de Tonini e Teresinha com a de Abelardo e Heloísa é necessária apenas a título de compreensão para esses relacionamentos ou paixões "platônicas" que costumam surgir entre pessoas ligadas à religião. No caso de Tonini e Teresinha, sabemos, ele era sacerdote católico e ela uma jovem adolescente, reconhecida e admirada na sua pequena cidade, que depois entrou para a vida religiosa. Diferente de Abelardo e Heloísa que chegaram a se casar e ter um filho, Tonini e Teresinha como veremos nessa parte do trabalho, não assumiram nem para eles mesmos nem publicamente o sentimento que alimentavam um pelo outro. Para mais informações sobre a vida de Abelardo e Heloísa, Ver: ESTEVÃO, José Carlos. Abelardo e Heloísa. São Paulo: Paulus, 2015.
}

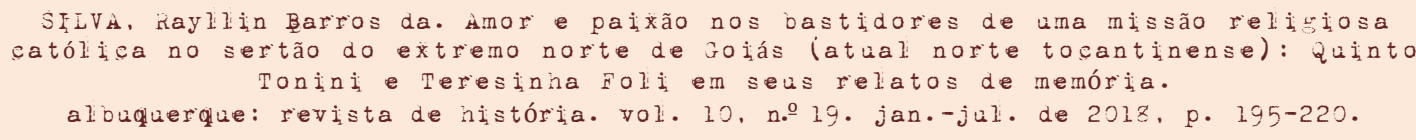


Por que consideramos importante abordar e desvelar o amor que existiu entre os dois personagens como principal problemática deste estudo? É possível que o amor que existiu entre os dois missionários terminou, junto com outros fatores, por fazer com que Quinto Tonini fosse afastado da missão religiosa e da "chefia" do catolicismo na região na época. Esse processo de afastamento do missionário resultou no "desmonte" do grupo de religiosos que eram muito bem "afinados" entre si. Teresinha e Tonini foram afetados.

Nos registros de memória tanto dela quanto dele é perceptível a relação muito próxima entre os dois. Ao observar essas narrativas, poderemos constatar que havia mais do que uma relação de amizade entre os dois. A relação contribuiu não de forma decisiva, mas contribuiu, para a decisão de afastá-lo da missão. Essa é a justificativa para a abordagem do sentimento entre os dois personagens neste estudo.

Vale dizer que o amor e paixão não constam em suas narrativas de forma clara, mas como será possível perceber neste estudo, uma quantidade considerável de indícios nos leva com tranquilidade a interpretar as narrativas de memória de ambos por esse viés. É possível essa interpretação tanto pelo teor das narrativas escritas quanto pelo que se pode interpretar mediante estudos que abordam a problemática do uso das autobiografias como fonte histórica. Nesse sentido, o historiador Weder Ferreira da Silva ao fazer uma análise da obra Memórias e Narrativas (auto) biográficas de Ângela de Castro Gomes e Benito Bisso Schmidt, reflete que:

Como apontou Giovanni Levi, nosso fascínio de arquivistas pelas descrições impossíveis de corroborar por falta de registros documentais alimenta não só a renovação da história narrativa, como também o interesse por novos tipos de fontes, nas quais se poderiam descobrir indícios esparsos dos atos e das palavras da vida cotidiana dos atores sociais. Os chamados escritos de si ou autorreferenciais vêm ganhando terreno no campo da historiografia, ilustrando, assim, as várias possibilidades e os resultados de pesquisas que utilizam tais escritos como fonte de investigação hístórica. ${ }^{4}$

${ }^{4}$ SILVA, Weder Ferreira. Resenha de: GOMES, Ângela de Castro; Schmidt, Benito Bisso (Org.). Memórias e Narrativas (auto)biográficas. Revista Brasileira de História, 2011. Disponível em:<http://www.scielo.br/scielo.php?script=sci_arttext\&pid=S0102-01882011000100017>. Acesso em: 10 de Nov. de 2016, p.1. 
Conforme refletiu Silva, na ausência de registros documentais de natureza tradicional, novos tipos de fontes como dados autobiográficos corroboram para novas interpretações, mediante o que ele chama de "indícios esparsos" dos atos da vida dos atores sociais, note-se para este estudo, os atores são Teresinha e Tonini. Os indícios existem e não faltam para a construção de nossa interpretação sobre o amor alimentado entre os dois atores da missão.

Terezinha de Jesus Nóbrega Foli era de família tradicional da cidade de Filadélfía, segundo principal centro da missão orionita. Quinto Tonini quando chegou à cidade foi na casa dela que se hospedou. Começava, desde a sua chegada em 1952, o convívio entre os dois. A relação entre os dois, pelo menos publicamente, foi sempre retratada como de dois amigos e durou o resto da vida dele, até sua morte. Logo após o desaparecimento de Quinto Tonini, Teresinha Foli decidiu falar, ou melhor, escrever. E escreveu dois livros de memória, o último é objeto de reflexão deste estudo.

Esse livro de memória intitulado Meandros da Verdade, título por sinal curioso e instigador, foi editado e lançado no início do ano de 2003, três anos após a morte de Quinto Tonini. É uma autobiografia. É como se Teresinha se sentisse mais a vontade para escrever e de fato escreveu. "Abriu" o seu coração, mas só uma parte, talvez ainda por receio. Neste estudo, analisaremos suas narrativas e buscaremos desvelar a outra parte do "coração" da então freira orionita. Sobre a decisão de Terezinha de "quebrar" o silêncio, ela narrou que:

Segundo Tagore, "a verdade levanta contra si a tempestade que espalha suas sementes em todo lugar". Esta frase expressa com clareza os motivos que me levaram a calar, guardando, sob a custódia do siliêncio, a verdade que hibernou oculta por trás das nuvens escuras da calúnia e da difamação, nuvens essas que ofuscaram, em parte, a vida do sacerdote Pe. Quinto Tonini. A prudência pesava sobre o receio de levantar, então, a tempestade. Antes de tomar a decisão de falar, pedi a Deus que me mostrasse sua vontade e que me desse luz e coragem para executá-la. ${ }^{5}$

Essa primeira manifestação de Teresinha é uma explicação para a decisão dela de se manifestar, depois de tanto tempo, sobre os acontecimentos que tinham envolvido a figura de Tonini, acontecimentos como a "trama" que foi artículada pelos superiores da congregação com o objetivo de afastá-lo da missão orionita e da

${ }^{5}$ FOLI, Teresinha de Jesus Nóbrega. Meandros da Verdade. Fortaleza: GM, 2003. p.12. 
liderança da Igreja no antigo extremo norte goiano na época. Ela resolveu escrever sobre si e sobre os acontecimentos. Mas por que Teresinha tomou a decisão de escrever? Os estudos autobiográficos ajudam a entender a decisão de Teresinha. Segundo Contardo Calligaris:

Diários íntimos e autobiografias são escritos por motivos variados: respondem a necessidades de confissão, de justificação ou de invenção de um novo sentido. Frequentemente, aliás, esses três aspectos se combinam. ${ }^{6}$

A partir da reflexão de Calligaris, que a autobiografia de Teresinha, a decisão de falar como ela mesma escreveu, partiu de dois motivos: primeiro justificar a vida dela e consequentemente, atribuir a sua própria vida e a de Tonini um sentido novo. Teresinha pareceu esclarecer, sob a ótica dela e mediante seus diálogos com Tonini, o que tería sido "tramado" para justificar o afastamento deste último do seu cargo. Mas nessa parte deste estudo não é o foco essa "trama" contra Tonini, mas o sentimento que ela alimentou por ele e ele por ela: a "trama" do amor que enlaçou os dois personagens da missão orionita na sua primeira década e continuou até a morte do religioso.

Como ocorreu o primeiro encontro entre os dois personagens? Teresinha em sua narrativa apresenta o momento:

De repente entra aquele sacerdote alto, jovem, vestido numa batina preta e grossa, trazendo no braço uma capa longa, também preta e, na mão, uma pasta de alça pequena. Em silêncio, eu a tudo observava. Aquele padre tinha alguma coisa que me chamava a atenção. ${ }^{7}$

Como é possível observar na narrativa de Teresinha, ela "guardou" em sua memória o momento do primeiro encontro com Tonini nos mínimos detalhes: a cor da roupa e até os pertences do sacerdote. Afirma em sua narrativa que observava

${ }^{6}$ CALLIGARIS, Contardo. Verdades de Autobiografias e Diários íntimos, 2013. Disponível em:<http://bibliotecadigital.fgv.br/ojs/index.php/reh/article/view/2071/1210>. Acesso em: $12 \mathrm{de} \mathrm{Nov.}$ de 2016. p.45.

${ }^{7}$ FOLI, Teresinha de Jesus Nóbrega. Meandros da Verdade. Op.cit. p.3. 
tudo, o que demonstra num primeiro momento o interesse em observar aquele homem que acabara de chegar a sua casa. Uma coisa está clara na narrativa: a intenção de Teresinha de expressar em seu registro autobiográfico que algo no padre chamou a sua atenção. Seria o que se denomina costumeiramente de "paixão à primeira vista?". Parece-nos que sim.

Tempo depois Teresinha resolveu procurar Tonini. Sobre o encontro ela narrou que:

Não dava mais para caminhar sozinha daquela forma. Em casa já começavam a perceber meu retraimento. Resolvi procurar Pe. Tonini, às escondidas, na Casa Paroquial. Eu tinha pavor em desnudar meu interior. Ele me fez sentar à sua frente. Tive a impressão - quase certa - que já aguardava aquele momento. Não lhe contei minha luta interior. Limitei-me a pedir que me ajudasse e orientasse à procura de uma Congregação que não fosse a das Capuchinhas, a única que eu conhecia de perto. Ele não me desaconselhou, mas fez-me ver que eu tínha a saúde frágil para o rigor dos conventos. Não abri, como desejava, nem mesmo uma fresta da janela de minha alma. ${ }^{8}$

A narrativa do primeiro diálogo entre Teresinha e Tonini é revelador em vários sentidos. Ela informa que na sua casa seus parentes já estavam percebendo algo de diferente nela mesma: uma mudança de comportamento. Seria o fato dos parentes de Teresinha já terem percebido algo de diferente nela em relação ao missionário? Ela informa que resolveu conversar com Tonini na casa paroquial e, surpreendentemente, diz que foi um encontro às escondidas. Por que Teresinha haveria de se encontrar com Tonini sem que ninguém visse ou soubesse? Haveria algo a esconder entre os dois?

Teresinha diz que "não dava mais para caminhar sozinha daquela forma". Teria ido encontrar-se com Tonini para dizer-lhe do seu amor? Essa hipótese é possível. Na narrativa Teresinha não registrou o verdadeiro motivo da visita à Tonini, pelo menos não escreveu. Sobre a estratégia do que se quer falar e também do que se quer calar nos registros autobiográficos, Maria Helena Menna Barreto Abrahão reflete que:

\footnotetext{
${ }^{8}$ Ibidem, p. 5.
} 
Não se trata de uma mera descrição ou arrumação de fatos, mas de um esforço de construção (e de reconstrução) dos itinerários passados. É uma história que nos contamos a nós mesmos e aos outros. $\bigcirc$ que se diz é tão importante como o que fíca por dizer. $\bigcirc$ como se diz revela uma escolha, sem inocências, do que se quer falar e do que se quer calar. ${ }^{9}$

Conforme observa Abrahão, ao interpretar os registros autobiográficos, não se deve procurar fazer uma simples "arrumação de fatos", mas segundo ela pontuou, é um esforço para a reconstrução de histórias de vidas passadas. Sabendo ainda que, nos registros autobiográficos, o que está dito é tão importante quanto o que não está. De fato, cremos que muitas coisas escreveu Teresinha, mas muitas coisas podem ter sido omitidas também, daí o esforço deste estudo em buscar reconstruir a história entre os dois missionários.

Teresinha prossegue em sua narrativa relatando que tinha medo de "abrir" o seu interior. Para desviar o sentimento que estava alimentando pelo missionário, pede a ele conselhos quanto à sua ideía de entrar para a vida religiosa. Como observado por ela, não queria fazer parte das irmãs capuchinhas então sediadas no lado maranhense. Mas por quê? Sendo a justamente congregação religiosa onde havia feito os seus estudos e ela já conhecia internamente? Teria ela optado entrar para a vida religiosa na congregação orionita como estratégía para poder ficar mais perto de Tonini?

Tonini também desaconselhou Teresinha de ingressar na ordem das irmãs capuchinhas. $\bigcirc$ fato de Tonini orientar Teresinha para que não entrasse na ordem capuchinha pareceu ter um objetivo certo: fazer com que ela ingressasse na congregação das irmãs orionitas. E foì o que aconteceu. Teresinha Foli após a conversa com Tonini ingressou na Congregação das Pequenas Irmãs Missionárias da Caridade, nome canônico das freiras orionitas. A partir daquele momento, Teresinha Foli, dentro do grupo das irmãs orionitas, passava a se chamar Maria Goretti, seu nome religioso. Daquele momento em diante Teresinha ingressou na congregação feminina de Dom Orione: estava "selada" a "parceria" e a convivência entre os doìs, convivência que se estendeu até a morte de Tonini, quase cinquenta anos depois.

É possível que o sentimento que havia entre os dois a partir de um determinado momento passou a ser percebido pelos religiosos da missão orionita

\footnotetext{
${ }^{9}$ ABRAHÃO, Maria Helena Menna Barreto. Memória, Narrativas e Pesquisa Autobiográfica. História da Educação. ASPHE/FaE. Pelotas: UFPel, 2003, p.86.
} 
no antigo extremo norte goiano na época. Basta observarmos quando Teresinha ao se referir à sua superiora em Tocantinópolis, escreveu que:

Certo dia, ao voltar da aula, a Superiora, Irmã Clotilde, deu-me a notícia que tinha tudo para me encher de satisfação, não fosse o tom irônico que havia em sua voz: Sabe, Suor Maria Goretti, quem vai ser o Administrador Apostólico? Não, respondi. Ela disse: Dom Quinto Tonini. No que falei: Ótimo, murmurei. Continuei meu caminho com livros e cadernos nas mãos e fui digerir a notícia. procurando descobrir o que haveria por trás daquela comunicação fora do contexto de nossa vida diária, feita com tanto sarcasmo, que ela não soube ou não quis esconder. ${ }^{10}$

No diálogo entre a superiora das irmãs orionitas em Tocantinópolis e Teresinha Foli, que como irmã orionita respondia pelo nome de Maria Goretti, observa-se claramente que a forma da superiora ao se dirigir a ela já demonstrava como definiu Teresinha, uma "ironia" e "sarcasmo". Ou seja, a superiora pareceu já saber do sentimento que existia entre os dois missionários orionitas: Teresinha e Tonini. É possível que, àquela altura, já poderia ser de conhecimento de membros da congregação a estreita relação entre os dois.

Outra narrativa faz crer que outros missionários sabiam do sentimento que existia entre os dois, esse missionário foi Pacífico Mecozzi, aliado de Tonini na missão. Mecozzi ao saber que Teresinha Foli estava em Niterói e que Tonini estaria de passagem pelo Rio de Janeiro a caminho da Espanha, a pedido de Tonini, tratou de acertar um encontro entre os dois, o que representou o último entre eles em solo brasileiro. Sobre a ajuda do missionário Mecozzi para o encontro, Teresinha narrou:

A visita foi rápida. Nós nem chegamos a entrar em casa. Conversamos fora, à sombra das mangueiras. Quando Pe. Tonini me narrou, depois de alguns anos, como chegou até onde eu estava através de mais um "anjo protetor", ele, Padre Pacífico, já não estava mais entre os vivos. Senti-me frustrada. Queria ter percebido tudo isso a tempo de demonstrar ao Pe. Pacífico minha gratidão, ao menos por um instante. ${ }^{11}$

\footnotetext{
${ }^{10}$ FOLI, Teresinha de Jesus Nóbrega. Meandros da Verdade. Op.cit. p.7.

${ }^{11}$ Idem, ibidem. p.22.
}

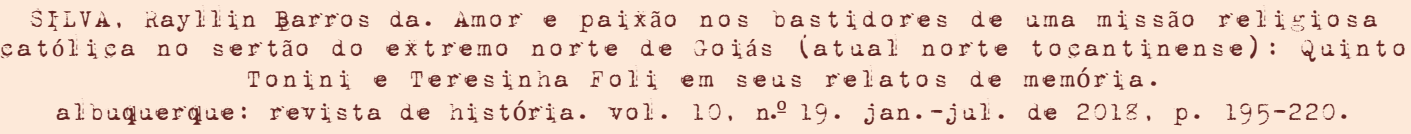


Se relacionarmos a narrativa acima com a anterior, quando do diálogo entre Teresinha e a superiora das irmãs orionitas em Tocantinópolis, pode-se dizer com convicção que o sentimento entre os dois missionários já era de conhecimento de outros religiosos da congregação orionita. Parece-nos que não havia nada mais em completo segredo. Nessa narrativa, Teresinha ainda se lamenta não ter tído a oportunidade de agradecer ao missionário Mecozzi por sua ajuda para que o encontro acontecesse entre Tonini e ela em Niterói, pois Mecozzi morreu antes que ela pudesse agradecê-lo.

Portanto, parece que o sentimento entre os dois já era conhecido por outros membros da congregação. Logo as consequências começaram para Teresinha Foli. Ela narra ter sido perseguida dentro do grupo das irmãs orionitas ao relatar:

Mas uma coisa começou a chamar minha atenção: após sua ausência, o relacionamento da Superiora comigo começou a se complicar. Indiretas que eu não compreendia, clima de tensão. Meu moral estava por terra. Optei pelo caminho que a pouca experiência de vida religiosa apontava como o mais seguro para andar sem tropeços: o do silêncio. Finalmente fui chamada pela Superiora, que me comunicou a notícia de minha permuta por outra religiosa, que já se encontrava a caminho: Irmã Amor Dei. colega em meus tempos de Colégio. ${ }^{12}$

Como é possível perceber na narrativa de Teresinha, ela começou a sentir-se perseguida pela sua superiora. Foi inclusive transferida de Tocantinópolis, sede da missão. Estaria sendo punida por sua relação de proximidade com Tonini ou mesmo o seu amor? Cremos que sim. Essas foram as punições impostas à Teresinha Foli: primeiro indiretas, insinuações, segundo passou a viver como ela mesmo destacou, um clima de tensão com seus superiores e, por último, acabou sendo transferida de Tocantinópolis, principal sede da missão orionita na região e época.

Nas narrativas seguintes é possível perceber que Teresinha demonstrou preocupação com a possibilidade de outros religiosos da congregação orionita ter conhecimento de seu sentimento por Tonini e desse último por ela. Parece-nos que àquela altura não dava mais para esconder a situação. Vale dizer que nos estudos autobiográficos há uma ligação indivisível da dimensão do individual com o social. Sobre essa relação, Maria Helena Abrahão reflete que:

\footnotetext{
12 Ibidem, p.10.
} 
Esta dialética pode, igualmente, ser encontrada em Ferrarotti, quando afirma que, nos estudos autobiográficos, fica clara a imbrição já referida entre o eu pessoal e o seu social, permitindo reconstruir os processos que fazem de um comportamento a síntese ativa de um sistema social a interpretar a objetividade de um fragmento da história social a partír da subjetividade não iludida de uma história individual. ${ }^{13}$

Conforme observou Abrahão, o eu e o social estão correlacionados nos estudos autobiográficos, são, portanto, dimensões inseparáveis. Portanto, a relação de Teresinha com o entorno dela, no caso a vida religiosa e os religiosos da congregação orionita, começou a deixá-la preocupada. Seria a preocupação que a fez não revelar de forma clara a paixão que ambos alimentavam um pelo outro? É possível que sim.

Mesmo após o afastamento de Teresinha e Tonini da missão orionita do extremo norte goiano eles continuavam se encontrando e os encontros aconteceram repetidas vezes. Teresinha narra o primeiro encontro deles após a transferência dela de Tocantinópolis, quando em Santa Catarina, recebeu a visita de Tonini que acabara de deixar a chefia da missão em Goiás e estava a caminho do Uruguai. Segundo ela:

Depois de deixar Tocantinópolis fui destinada para trabalhar em Siderópoliss, Santa Catarina. Certa manhã a campainha tocou. Fui atender e deparei-me com o Pe. Tonini. Perguntei por amigos e parentes que eu havia deixado em Goiás. Notei que ele estava taciturno, estranho, diferente. Quando lhe pedi se podia levar uma carta minha ao papai, ele respondeu: Não vou mais voltar para o Goiás. Estou aqui de passagem para o Uruguai, meu novo campo de trabalho. Como? Está me dizendo que deixou a missão e vaí deixar também o Brasil? Sim, renunciei. Pe. Tonini contou-me os motivos que o levaram àquela resolução. Não percebi nele nenhum sentimento de revolta, mas uma tristeza profunda, que procurava esconder. ${ }^{14}$

13 ABRAHÃO, Maria Helena Menna Barreto. Memória, Narrativas e Pesquisa Autobiográfica. História da Educação. Op.cit. p.83.

${ }^{14}$ FOLI, Teresinha de Jesus Nóbrega. Meandros da Verdade. Op.cit. p.12. 
Como se pode observar nessa narrativa de Teresinha, mesmo com a transferência sua e de Tonini da missão orionita no extremo norte goiano eles continuaram a se encontrar. Interessante notar que o missionário Tonini foi diretamente a Santa Catarina rever Teresinha. Parece-nos que foi mais que uma simples visita, demonstrou a existência de um sentimento que havia entre os dois.

Vale dizer que inúmeros encontros ainda aconteceram entre os dois, inúmeros. Por uma questão de "economia", optamos por não mensurar todos os encontros. Mas eles se deram tanto no Brasil como no exterior, exemplo dos encontros ocorridos na Europa. Tonini e Teresinha se encontraram e com frequência também fora do Brasil. Na Europa os encontros ocorreram, por exemplo, em Nevacerrada (Espanha), Nápolis, Sanremo e Pompéia, essas três últímas, cidades italianas (FOLI, pp.24/25; 27/28; 39; 43/44).

Num desses encontros, Teresinha não escondeu sua alegria e seu sentimento. Fica mais evidente nossa interpretação de que havia muito mais do que amizade entre eles dois. Sobre o momento ela narrou:

Aquele encontro foi uma injeção de ânimo. Pela primeira vez não consegui esconder "minhas pérolas", que rolaram indiscretas, deixando-me envergonhada. Ele era a única pessoa a quem ainda eu tinha coragem de falar sem receio de ser apunhalada pelas costas. Não havia mais necessidade de tantas palavras. ${ }^{15}$

A narrativa de Teresinha sobre o encontro com Tonini é muito importante para nossa interpretação neste estudo. Ela diz não ter escondido suas "pérolas" e que por isso sentiu vergonha. Ela não explica em seus escritos o que seriam essas "pérolas", mas é possível que foram seus sentimentos, sua paixão pelo missionário Tonini, daí ter ficado envergonhada, ao que parece. Ela encerra sua narrativa afirmando que no encontro não havia "mais necessidade de palavras". Mas por que não teria mais necessidade de palavras? Num encontro entre duas pessoas sendo dois amigos, não se conversa?

Se não haveria mais necessidade de palavras, certamente, é porque o sentimento, a felicidade do reencontro falaria por si só. Na ausência de palavras, falaria o sentimento. Mesmo quando não podiam se encontrar pessoalmente, os dois trocaram correspondências mútuas. Em alguns momentos da narrativa de

${ }^{15}$ FOLI, Teresinha de Jesus Nóbrega. Meandros da Verdade. Op.cit. p.25. 
memória de Teresinha, parece que esse hábito que eles tinham de trocar correspondências era muito comum.

Sobre as correspondências frequentes entre os dois, apresentamos apenas alguns exemplos de que ambos se comunicavam com frequência, ora dando notícias um para o outro, ora informando mudança de endereço, conforme pode-se observar nesse conjunto de quatro narrativas onde Teresinha escreveu que: "Ao chegar no Uruguai, Pe. Tonini escreveu-me dando o seu endereço" (FOLI, 2003, p.13), em outro momento ela escreveu: "E nós continuamos a nos corresponder, sem falar de passado, nem de futuro, mas de coisas amenas, dando-nos força mutuamente" (Tbidem, p.19), em outra parte da sua narrativa ela narrou que "Depois que chegou na Espanha, Pe. Tonini mandou-me seu endereço. Nossa correspondêncía resumia-se a cartões postais escritos no verso. Era uma forma de nos mantermos em sintonia" (Ibidem, p.22), e finalmente em outra ela diz: "Em janeiro de 1985 recebi uma carta do Pe. Tonini onde ele comunicava seu retorno para a Itália, acrescentando que gostaria de receber minha visita" (Tbidem, p.27).

Apresentamos apenas algumas narrativas de como os dois missionários se correspondiam. Estabeleceu-se, sem sombra de dúvidas, um laço inquebrável entre eles. Um laço que só poderia ser explicado pela existência de sentimentos como amor, paixão, afeto. Mas num determinado momento os superiores da congregação orionita no Brasil resolveram "colocar um fim" nos contatos entre Teresinha e Tonini. Uma correspondência enviada por Tonini que estava no Uruguai para Teresinha em Siderópolis, Estado de Santa Catarina, foi interceptada por um sacerdote orionita que residia no sul do país. Segundo Teresinha:

Quando entrei na Casa Paroquial, encontrei o Pe. Pedro Pelanda na sala, sentado, tendo uma carta aberta nas mãos. Acomodei-me numa cadeira a seu lado. Imediatamente reconheci a letra da carta, colocando-me em estado de alerta. Pe. Pedro começou a me explicar, com a solenidade de quem "estava salvando a pátria", que havia tirado aquela carta das mãos do Pe. Nello Bonomi, quando viu que estava endereçada a mim. ${ }^{16}$

Como se pode perceber na narrativa acima, a carta de Tonini à Teresinha foì desviada por membros da congregação orionita. Mas por que haveria a congregação de desviar correspondências entre os dois religiosos? A resposta mais apropriada estava no fato que os membros mais "graduados" da congregação orionita no Brasil

\footnotetext{
16 Ibidem, p. 15.
} 
já sabiam de algo entre os dois religiosos e a estratégia de desviar suas cartas, teria como objetivo ou confirmar a relação ou saber de algo a mais, como por exemplo, os planos que poderiam existir entre Tonini e Teresinha.

Esse não foì o único caso de interceptação de correspondências entre Teresinha e Tonini. Tempos depois, quando ela residia em Fortaleza, outra correspondência entre os dois foi interceptada por ninguém menos que o superior dos orionitas no país na época, conforme se pode observar na narrativa quando Teresinha escreveu:

Certo dia um carro buzinou em frente ao nosso portão. Era um táxi. No banco de passageiro estava sentado um senhor, tendo nas mãos um mapa da cidade. $\bigcirc$ passageiro disse que procurava a residência de Teresinha Nóbrega. $\bigcirc$ recém-chegado explicou que tinha ido à procura de um livro que tinha sido despachado pelo Correio em meu nome, mas que na verdade era para ele. Alberto acompanhou-o até o táxi, que continuava aguardando. Depois que se despediu e se acomodou no carro, o Pe. Antônio Lemos (sim, ele mesmo), virou-se e disse: Eu sou o provincial dos orionitas. Só então Alberto percebeu que havia sido ludibriado. Era tarde. $\bigcirc$ táxi estava longe. ${ }^{17^{1}}$

Ao observar a narrativa de Teresinha, era a segunda interceptação de correspondências entre ela e Tonini. Dessa vez havia uma diferença: o próprio provincial, que é o superior dos religiosos no Brasil, pessoalmente, realizava a "tarefa". A "entrada em cena" do orionita mais "graduado" no país no momento, refletiu bem a preocupação que Teresinha e Tonini representavam para a congregação. A correspondência violada foi o que Tonini chamou de "datiloscrito": conjunto de escritos em língua italiana de suas memórias. Páginas datilografadas que Teresinha iria realizar a tradução para o português. $\bigcirc$ texto, na metade dos anos 1990, foí publicado sob o título 'Entre Diamantes e Cristais', considerado o principal relato de memória da missão orionita da época.

texto furtado foi para as mãos da congregação. Não chegou ao destino, a residência de Teresinha em Fortaleza. Logo depois, Tonini informado da violação, disponibilizou outra cópia para que Teresinha fizesse a tradução. Interessante observar sobre esse livro, que ele não foi publicado pela congregação orionita, como era desejo de Tonini na época, o que é estranho, visto o livro ser considerado a

${ }^{17}$ FOLI, Teresinha de Jesus Nóbrega. Meandros da Verdade. Op.cit. p.29.

SFLVA, Kaylitin Barros da. Amor e paixão nos bastidores de uma missão relín ísa católica no sertão do extremo norte de Goís (atual norte tocantinense): Quinto Tanini e Teresinha Foli em seus relatos de memória.

albuquerque: revista de história. val. 10, n.o 19. jan.-jul. de 2018. p. 195-220. 
principal fonte sobre a primeira década da missão no extremo norte goiano. Nas páginas do mesmo não há nenhuma referência ao apoio da congregação para a sua publicação, o que faz acreditarmos que foi uma publicação independente, ou seja, bancada pelo próprio Quinto Tonini

Como vimos, então, correspondências entre Tonini e Teresinha foram violadas. $\bigcirc$ que leva a crer que esse fato pode, somado às perseguições, transferências e insatisfações, levado os dois missionários a se sentirem insatisfeitos com a congregação a que eles pertenciam. Não sabemos exatamente o motivo, mas Teresinha Foli decidiu se desligar da congregação das irmãs orionitas em 1971, doze anos após o afastamento de Quinto Tonini do comando da missão orionita no extremo norte goiano. Conforme ela narrou:

Em 1971 escrevi-lhe dizendo que ia deixar a Congregação, definitivamente. Não tinha mais sentido minha vida ali, remando sempre contra a maré, excluída de tudo. Ele me respondeu: "não achas tarde para começar tudo de novo?" Eu respondi: "Ainda não cheguei aos 40 anos e tenho garra o suficiente para recomeçar do zero. Depois escrevo-lhe dando o endereço do pensionato onde vou morar. $^{18}$

Como se pode perceber na narrativa, Teresinha Foli em outra correspondência comunica a Quinto Tonini a sua decisão de abandonar a congregação orionita no ano de 1971. Ao comunicar a ele a decisão, observa-se a importância do missionário para a ainda freira. Não deixa de ser uma consideração com Tonini a atitude de Teresinha. Mas a atitude de Teresinha de se desligar da congregação levanta algumas possibilidades, como por exemplo: teria Teresinha comunicado Tonini a decisão de forma que ele também a seguisse na decisão e também fazer o mesmo? Seria um "alerta" como: fiz a minha parte, e você? Não buscou, com o abandono da vida religiosa, forçá-lo a fazer o mesmo para, a partír daí começarem uma nova vida, juntos? E perfeitamente possível.

Naquele momento, não estavam mais tão próximos. Ele como já escrito, havia se mudado para a Europa. Esses fatores podem ter influenciado na decisão de Teresinha Foli de abandonar o hábito religioso e a sua congregação. Essa é nossa interpretação para a decisão dela. A partír daí, Teresinha Foli resolveu dar uma

${ }^{18}$ FOLI, Teresinha de Jesus Nóbrega. Meandros da Verdade. Op.cit. p.26.

SFLVA, Kaylitin Barros da. Amor e paixão nos bastidores de uma missão relituiosa católica no sertão do extremo norte de Goís (atual norte tocantinense): Quinto Tanini e Teresinha Foli em seus relatos de memória.

albuquerque: revista de história. val. 10, n.o 19. jan.-jul. de 2018. p. 195-220. 
reviravolta em sua vida como ela mesma narrou, após deixar a congregação e consequentemente a vida religiosa:

Continuei residindo em Niterói. Conclui o Curso de Serviço Social na Universidade e o Curso de Italiano. Casei-me. Prestei concurso público e fui admitida para trabalhar como assistente social do INPS. Em 1980 pedi transferência e nos mudamos para Fortaleza. ${ }^{19}$

A partir da narrativa de Teresinha, pode-se inferir que ao abandonar a vida religiosa ela parece ter decidido redirecionar muitas coisas na sua vida daquele momento em diante. $\bigcirc$ que foi natural. Ela afirmou ter continuado seus estudos ao adquirir uma graduação e disse ter estudado língua italiana. Mas por que decidiu estudar o italiano? Visto que acabara de abandonar o hábito religioso e não era mais freira? Teria sido um desejo/projeto de conhecer com mais propriedade a língua de Tonini que era italiano? E possível. Ela narra que entrou para o serviço público e decidiu casar-se.

Nas duas últimas narrativas anteriores Teresinha mostra em seu registro autobiográfico ter redirecionado consideravelmente sua vida. Ela quis que essa mudança fosse registrada e de fato o foi. Sobre essas mudanças nas trajetórias de vida de quem se autobiografa, o historiador Weder Ferreira da Silva reflete que:

As narrativas autobiográficas evidenciam de forma clara como a trajetória de um indivíduo varia no tempo, o que atesta, mais uma vez, aquilo que Pierre Bourdier chamou de "iliusão biográfica", a ilusão de uma linearidade e coerência do indivíduo. Dito isto, cabe ainda ressaltar a proposição de Paul Ricouer, para quem a história de vida de um indivíduo não cessa de ser refigurada por todas as histórias verídicas ou fíctícias que um sujeito conta de si mesmo. Essa refiguração faz da própria vida um tecido de histórias narradas. ${ }^{20}$

19 Ibidem, p.27.

20 SILVA, Weder Ferreira. Resenha de: GOMES, Ângela de Castro; Schmidt, Benito Bisso (Org.). Memórias e Narrativas (auto)biográficas. p.2. 
Conforme observou Silva, nas narrativas autobiográficas a trajetória dos sujeitos varia de acordo com o tempo. Não existe, portanto, linearidade e coerência de acordo com o autor. Exatamente como ocorreu com Teresinha, pois como vimos nas suas narrativas posteriores, ela abandonou a vida religiosa, casou-se, se tornou servidora pública.

Quando nos debruçamos sobre a narrativa em que Teresinha teria casado, imaginamos que estava desconstruída a hipótese que já no momento apontava para a existência de um sentimento amoroso entre ela e Tonini. Então procedemos a novas leituras das narrativas e cruzando-as, concluímos que o fato de Teresinha ter se casado apenas corroborava para nossa hipótese pré-estabelecida. Ou seja, ao casarse, a ex-freira teria apenas buscado uma companhia para a sua vida. Talvez por medo da solidão, porque sabia que com o abandono do hábito religioso, começava ali uma "nova vida" e seu "sonho" de unir-se à Tonini ainda não tinha se concretizado. Essa é a hipótese para a decisão que levou Teresinha a casar-se.

que reforça essa hipótese é apresentado pela própria Teresinha, por suas atitudes e decisões. Atitudes como o fato de mesmo depois de casada ter continuado e com muita frequência a se comunicar com Tonini e, decisões como, por exemplo, e não menos importante, deixar seu marido no Brasil e ir para a Europa com uma única finalidade: visitar Tonini. Teresinha mesmo depois de casada intensificou suas visitas à Tonini no "velho" continente. Essas atitudes de Teresinha são muito importantes para o sustento da nossa hipótese. Assim, anos depois de casada, residindo em Fortaleza com seu marido, Teresinha surpreende de novo, conforme se pode observar na narrativa:

Aposentei-me em 1994 e escrevi-lhe, com a seguinte proposta: "Vamos trabalhar por um ou dois anos da África? Sei que os padres de Dom Orione têm várias casas lá. Eu posso ensinar e colocar minha profíssão à dísposição da comunidade lá. Meu marido não se opõe e ficaria aqui, cuidando de nossos interesses."21

Como se pode observar na narrativa de Teresinha, ela continua se comunicando com Tonini mesmo depois de casada. Mas o mais surpreendente no registro é a proposta que ela faz para o missionário: irem morar um tempo na África. Como uma mulher casada propõe deixar seu marido e país para passar alguns anos em outro país com outro homem? Mesmo esse último sendo um padre? Como se

${ }^{21}$ FOLI, Teresinha de Jesus Nóbrega. Meandros da Verdade. Op.cit. p.27.

SFLVA, kaylitin Barros da. Amor e paixão nos bastidores de uma missão relíniosa católica no sertão do extremo norte de Goís (atual norte tocantinense): Quinto Tanini e Teresinha Foli em seus relatos de memória.

albuquerque: revista de nistória. val. 10, n.o 19. jan.-jul. de 2018. p. 195-220. 
pode explicar uma proposta dessas? Teria Teresinha lançado mão de uma última tentativa de ir viver com Tonini? Parece-nos que sim.

Ela buscou justificar a proposta dizendo que poderia colocar os seus conhecimentos à serviço daquele continente e que, seu marido não se mostrava contrário à ideía. Consideramos não conseguir explicar a anuência do marido de Teresinha, exceto, mediante uma hipótese: a de que sabendo do sentimento que sua mulher alimentava por outro homem, no caso, o missionário Tonini, ele estaria "liberando" Teresinha para que buscasse sua felicidade, seguisse o seu caminho, no caso na África, muito longe do Brasil.

Mais curiosa foi a resposta de Tonini para a proposta de Teresinha, conforme ela, Tonini respondeu: "Menina, esqueceu que eu sou mais velho que você 12 anos?" (Ibidem, p. 27). Consideramos a resposta de Tonini à proposta de Teresinha de irem morar na África curiosa pelo fato que a resposta, dada naqueles termos, apenas demonstra a "saia justa" que Teresinha acabara de colocar Tonini. Ele ficou, certamente, desconcertado com a atitude de Teresinha. Tanto ficou que respondeu não de uma forma explicativa, justificando o fato de não poder ir, mas respondeu invocando a sua idade, como exposto, doze anos mais velho que ela.

Outra questão a se observar na resposta de Tonini foi a forma como ele a inicia, chamando Teresinha de "menina". Uma forma carinhosa e que demonstra a intimidade que havia entre os dois. Assim, depois da proposta de Teresinha, os dois voltaram a se encontrar na Itália, no encontro, percebe-se o surgimento de outro sentimento que estava ficando nos encontros: o arrependimento. Arrependimento não por terem se encontrado, é claro, mas por não terem "abertos" os seus corações naqueles momentos, conforme se pode observar:

Era a oportunidade que eu aguardava para desabafar, tirar as dúvidas, ouvir seus conselhos equilibrados, sinceros, humildes e seguros. $\bigcirc$ tempo passou rápido. Após o almoço fomos para a Estação de Nápolis, onde peguei o trem para Roma. Quando retornei ao Brasil, escrevi-lihe uma carta, lamentando não ter aproveitado aquela oportunidade para abrir o meu interior. Fiquei com remorso, ao ler a resposta: "Eu sou um tonto. Não percebi que você precisava de mim. ${ }^{22}$

${ }^{22}$ FOLI, Teresinha de Jesus Nóbrega. Meandros da Verdade. Op.cit. p.28.

SFLVA, Kaylitin Barros da. Amor e paixão nos bastidores de uma missão relitistosa católica no sertão do extremo norte de Goís (atual norte tacantinense): Quinto Tonini e Teresinha Foli em seus relatos de memória.

alouquerque: revista de história. vol. 10, n.o 19. jan.-jul. de 2018, p. 195-220. 
Conforme se pode observar, a partir de um determinado momento os encontros passaram a gerar remorso. Remorsos porque durante aqueles momentos ambos não abordavam abertamente o que sentiam um pelo outro. Nos encontros parecia que de tudo se conversava, sobre suas vidas, seus problemas, suas angústias, seus dilemas, mas ao que parece, nunca falavam do que sentiam um pelo outro. Pelo menos é o que se pode perceber nas narrativas de Teresinha. Mas por que não tratavam do que sentiam um pelo outro? $\bigcirc$ que os impedia de se "entenderem" nas oportunidades daqueles encontros? A única hipótese que temos é a do medo, da timidez de se declararem de forma definitiva um para o outro. Se é que já não tinham feito isso.

$O$ fato é que eles se encontravam. Ainda é importante notar que vez por outra nos encontros eles tinham certos cuidados para não serem mal "interpretados" pelos outros. Parecia uma necessidade de discrição entre eles, conforme se deu em um encontro entre os dois em Sanremo, Itália:

Na cozinha, ele pegou um pãozinho numa cesta que estava sobre aquele móvel. Tírou um pedaço e deu-me o outro, dizendo: "Prove este pão". Tírei um pedaço e pus na boca. Ele olhou para mim, com os olhos cheios de lágrimas e disse: "E pensar que estes pães estão aqui porque a comunidade os despachou do refeitório. Querem pão fresquinho. Onde está o voto de pobreza? Já pensou. Tetê, quantos pobres ficariam felizes se tivessem destes pães sobre a mesa?" Eu não disse uma palavra. Como muito pouco pão. Mas experimentei daquele. Estava bom. Era um pãozinho torrado, que não se fabrica no Brasil para o consumo em massa. Apressei-me em sair com ele dali, para evitar que fosse flagrado chorando. Que pensamentos aquela cena poderia provocar $?^{23}$

Algumas análises podem ser feitas sobre essa narrativa de Teresinha. Primeiro, vale observar que aquele foi o penúltimo encontro que se deu entre os dois. Aproximava-se o fim de Tonini. Portanto, ele num momento de emoção chora. Ela diz que ele tentou explicar as lágrimas aludindo para o fato que muitos não tinham pães para comer e aqueles pães ali estavam disponíveis. Será que a explicação era verdadeira para as lágrimas de Tonini? Seria mesmo aquele o motivo para a emoção?

\footnotetext{
${ }^{23}$ Ibidem, p.45.
}

SFLVA, kaylitin Barros da. Amor e paixão nos bastidores de uma missão relistiosa católica no sertão do extremo norte de Goís (atual norte tacantinense): Quinto Tonini e Teresinha Foli em seus relatos de memória.

albuquerque: revista de história. val. 10, n.o 19. jan.-jul. de 2018. p. 195-220. 
Nossa interpretação é que emocionado ao reencontrar Teresinha, ele não conseguiu conter a sua emoção e derramou suas lágrimas. Lágrimas ali explicadas por ele, buscando outra justificativa, que não a presença de Teresinha diante dele no momento. Outra interpretação que deve ser considerada, inferimos, é que Tonini possa ter sentido que aquele seria um dos últimos encontros entre eles. Isso é possível. E de fato foi o penúltimo encontro que ocorreu entre os dois.

Outra observação é a forma como ele se refere a ela: chama-a de "Tetê". Um diminutivo para o nome Teresinha. De novo, uma forma carinhosa de tratamento que a nosso ver, representa proximidade e mais, intimidade entre os dois. Por último, sobre essa narrativa anterior que retrata o que foi um dos últimos encontros entre eles dois, Teresinha diz ter saído logo com Tonini do lugar, estava preocupada com a possibilidade de alguém vê-lo chorando diante dela. Receou Teresinha de que a cena fosse presenciada por outras pessoas.

Como explicar, portanto, esse gesto de Teresinha? Só possuímos uma hipótese: sabendo ela do sentimento recíproco entre eles dois, as lágrimas de Tonini poderiam evidenciar, publicamente, o que ele sentia por ela. Na verdade, foi uma preocupação de preservá-lo de insinuações e fofocas, agora na Itália, já que insinuações e fofocas fizeram parte da vida deles no Brasil. Esse gesto, preocupação de Teresinha em preservar Tonini demonstra, mais uma vez, o carinho e 0 sentimento que ela guardava por ele, cremos.

No mesmo ano, 1999, a saúde do missionário Tonini se deteriorou. Teresinha resolveu voltar à Sanremo, na Itália, para vê-lo. Chegando lá ela foi para seus aposentos. Tonini não estava no momento, havia saído. Quando eles se encontraram, seria o último momento entre os dois. Sobre aquele momento Teresinha escreveu:

No dia seguinte, após o café da manhã fui ao encontro dele, no asilo. Encontrei-o sentado numa sala grande, uma espécie de escritório, que lhe estava reservada. Parado com uma estátua, olhava o vazio como se estivesse ausente. Ao ver-me na porta, encheu-se de vida e levantou-se para me saudar. Vê-lo retomar o ânimo e expandir a alegria que lhe era peculiar, ao menos por um pouco de tempo, compensava o sacrifício da longa e cansativa viagem que eu acabara de fazer. ${ }^{24}$

\footnotetext{
${ }^{24}$ FOLI, Teresinha de Jesus Nóbrega. Meandros da Verdade. Op.cit. p.47.
} 
Conforme se pode observar do último encontro entre Teresinha e Tonini, ele estava muito debilitado como ela mesma o apresentou em sua narrativa. Ela narra que ele ao vê-la, foi tomado por uma alegria contagiante. Parece-nos que Tonini pôde ter intuído que seria o último encontro entre os dois. Ela relata que ficou de igual forma alegre ao ver ele por um instante. Ao se aproximar o momento que veio a ser a despedida final entre os dois, Teresinha escreveu:

Passei a tarde conversando com ele. Como só havia ali uma cadeira, acomodei-me à sua frente, sentada no assoalho. Falei do meu retorno que se aproximava. Prometi-lhe voltar, se Deus assim o permitisse. Não consegui prosseguir. Fui assaltada pelas lágrimas indiscretas, que fugiam do meu controle. Ele continuou na posição em que se encontrava, sem mover-se, sem falar nada, mas atento. Parecia um rochedo. Não sei precisar quanto tempo durou aquele silêncio que se instaurou entre nós. Pareceu-me eterno. Finalmente tomei ânimo e o convidei a sairmos para ver o mar, que ficava vizinho, ao lado. Minha despedida final estava feita. $\bigcirc$ assunto encerrou-se ali, naquela tarde. Deixei Sanremo convicta que não mais nos veríamos. Acredito que Pe. Tonini também pensava da mesma forma. Dele eu guardo uma última imagem: deixando a estação, cabisbaixo, atrás do motorista da vila que nos trouxe até ali, sem se voltar para trás. ${ }^{25}$

Como se pode observar na narrativa de Teresinha, aquele momento de extrema emoção entre os dois marcou de fato a despedida entre eles. Ao que parece ambos tinham consciência que era a última vez que iriam se encontrar. De fato, foí. Mas alguns apontamentos precisam ser feitos dessa narrativa. Teresinha narra a emoção que viveu, cita as suas lágrimas que ela chamou de "indiscretas" e observou que ele não demonstrava nada, nenhuma reação, estava imóvel. Mas por que Tonini se manteve sem reação naquele momento?

Temos como hipótese duas interpretações: a do seu estado de saúde precário no instante, que poderia ter lhe tirado qualquer senso de racionalidade ou gesto emotivo. Segundo, um esforço dele para não demonstrar fraqueza. É mais plausível a primeira hipótese, a mais adequada. De qualquer forma, no último encontro quem "derramou" lágrimas foi Teresinha, no penúltímo encontro como vimos, foi Tonini. Foi a despedida, cada um agiu da sua forma, no seu momento. Cremos que se pode ainda hipotetizar que no último encontro entre os dois eles pudessem ter tratado

\section{${ }^{25}$ Ibidem, p.48.}

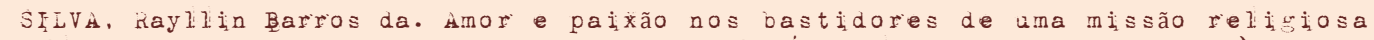
católica no sertão do extremo norte de Goís (atual norte tocantinense): Quinto Tonini e Teresinha Fali em seus relatos de memória.

alouquerque: revista de história. vol. 10, n.o 19. jan.-jul. de 2018, p. 195-220. 
do amor que ambos sentiam um pelo outro. Isso pode ter acontecido e ela optou em sua narrativa autobiográfica em não abordar de forma mais clara. Sobre essas omissões em registros autobiográficos, o historiador francês Philippe Artieres reflete:

Mas não arquivamos nossas vidas de qualquer forma, não pomos nossas vidas em conserva de qualquer maneira; não guardamos todas as maçãs da nossa cesta pessoal; fazemos um acordo com a realidade, manipulamos a existência: omitimos, rasuramos, riscamos, sublinhamos, colocamos em enxergo certas passagens, registramos apenas alguns acontecimentos, omitimos outros. ${ }^{26}$

Como destacou Artieres, quem se autobiografa costuma omitir informações, registra apenas o que lhe convém. Cremos que no último encontro entre Teresinha e Tonini pode ter ocorrido dos dois terem tratado do sentimento que ambos tinham um pelo outro. Mas Teresinha não abordou esse assunto em sua autobiografia. Por quê? Já sabemos que o registro autobiográfico de Teresinha foi escrito após a morte de Tonini. Talvez em respeito a sua memória, ou ainda em consideração à congregação orionita, Teresinha possa ter optado em não expor claramente o amor que existiu entre os dois, com o objetivo também de não constranger ela própria, nem a memória de Tonini.

Destacamos o que Teresinha apontou como "silêncio" que imperou num determinado momento da despedida. $\bigcirc$ silêncio diz muito. Foi a despedida final entre Teresinha e Tonini, eles sabiam que não se veriam mais. $\frac{1}{E}$ como se os dois, conscientemente, não quisessem por um momento expressar mais nada. A longa convivência que eles tiveram já teria sido o suficiente para eles, suficiente os encontros anteriores, as correspondências, as confidências. $\bigcirc$ silêncio deles pareceu ter falado pelo sentimento que havia.

Por fim, no encontro, ficou para Teresinha o que ela chamou de "última imagem": Tonini de cabeça baixa ao deixar o lugar. Essa última imagem de Tonini narrada por Teresinha pode gerar várias interpretações possíveis. Ficamos com uma: a da tristeza da despedida, da tristeza de terem alimentado por quase uma vida toda uma paixão, um amor platônico, um sentimento e que naquele últímo momento entre os dois, terem se dado conta de que não deram "um passo" além no caminho da felicidade deles, felicidade que poderia ter se dado com a união entre ambos, visto

\footnotetext{
${ }^{26}$ ARTIERIS, Philippe. Arquivar a Própria Vida, 2014. Disponível em: http://bibliotecadigital.fgv.br/ojs/index.php/reh/article/view/2061/1200>. Acesso em: 16 de Out. de 2016, p.3.
} 


\section{7}

que ela já tinha abandonado o hábito religioso, possivelmente, aguardando a mesma atitude dele, atitude que não veio a acontecer.

No ano seguinte, 2000, a situação do missionário Tonini se agravou de vez. Teresinha partiu imediatamente para a Itália:

Pe. Tonini foì transferido para o Hospital da Congregação, em Castagna, próximo de Gênova. Cheguei às 18 horas em Roma. Deixei minha bagagem entregue à guia e parti de trem para Gênova, onde cheguei ao amanhecer. Aquela quase certeza que tive em Sanremo um ano antes fez-me mudar o itinerário. Peguei um táxi para a Casa Provincial dos Padres, no Paverano de Gênova. Mais tarde prosseguiria até Castagna. Não foi necessário. Alí mesmo. Pe. Tonini fora velado, dois dias antes. Os parentes levaram seu corpo para sepultá-lo em sua terra natal. Cheguei tarde. Ele já havia partido? ${ }^{\text {7 }}$

A narrativa acima de Teresinha mostra seu esforço para encontrar Tonini ainda com vida. Mas ela não conseguiu. Estava assim, encerrada a relação que havia começado quase cinquenta anos antes, em Filadélfia, quando em 1952. Tonini se hospedou na casa dos pais de Teresinha Foli, quando ele chegou para assumir a paróquia católica da cidade, no contexto da missão orionita no antigo extremo norte goiano

Uma relação que começou entre Tonini e uma Teresinha ainda adolescente, que continuou entre Tonini e Teresinha já como freira e, terminou entre o já idoso Tonini e Teresinha ex-freira. Esses foram os caminhos vividos, traçados e cruzados entre os dois personagens orionitas, os expoentes de um amor que existiu entre eles no interior da missão católica orionita no antigo extremo norte de Goiás, na metade do século passado.

${ }^{27}$ FOLI, Teresinha de Jesus Nóbrega. Meandros da Verdade. Op.cit. p.49.

SFLVA, Kaylitin Barros da. Amor e paixão nos bastidores de uma missão relíniosa católica no sertão do extremo norte de Goís (atual norte tocantinense): Quinto Tanini e Teresinha Foli em seus relatos de memória.

albuquerque: revista de história. val. 10, n.o 19. jan.-jul. de 201z, p. 195-220. 


\title{
considerações finais
}

Como foi possível perceber ao longo deste estudo, os caminhos de Teresinha Foli e Quinto Tonini, foram sempre pavimentados por um sentimento amoroso, de carinho, de paixão, de afeto, mas também de respeito, consideração, amizade. Reservaram um tratamento respeitoso entre eles, sempre com o cuidado de não se expor publicamente. Mas esse cuidado, por vezes, não foi suficiente. Basta ver que Teresinha foi constrangida várias vezes, uma vez pela sua superiora quando trabalhava em Tocantinópolis, outras vezes por sacerdotes orionitas, quando da violação de correspondências entre ela e Tonini, uma vez em Siderópolis e a última em Fortaleza, já como ex-freira.

Como já dito anteriormente, as narrativas não demonstram de forma clara e inconteste a relação de amor entre Teresinha e Tonini. Mas é muito possível que relação e esse sentimento existiram. Alguns estudos sobre autobiografia ajudam a construir esse entendimento. Assim, para Maria Helena Abrahão:

\begin{abstract}
Ao trabalhar com metodologia e fontes autobiográficas, o pesquisador conscientemente adota uma tradição em pesquisa que reconhece ser a realidade social multifacetária, socialmente construída por seres humanos que vivenciam a experiência de modo holístico e integrado, em que as pessoas estão em constante processo de auto-conhecimento. Por esta razão, sabe-se, desde o início, trabalhando antes com emoç̃os e intuições do quer com dados exatos e acabados; com subjetividades, portanto, antes do que com o objetivo. Nesta tradição de pesquisa, o pesquisador não pretende estabelecer generalizações estatísticas, mas, sim. compreender o fenômeno em estudo, o que lhe pode até permitir uma generalização analítica. ${ }^{28}$
\end{abstract}

Conforme observou Abrahão, as fontes autobiográficas lidam com emoções antes do que com dados acabados, com subjetividades e não com objetividades. Daí esse tipo de fonte nos permitir relativa liberdade de interpretação para a construção de nossas narrativas. Foi o que buscamos fazer com a memória autobiográfica de Teresinha Foli. Ela não deixou escrito em suas memórias que amava Tonini, mas não precisou. No que chamamos "entrelinhas" essas palavras estão colocadas. E concordamos com Abrahão ainda quando diz que pesquisadores podem, a partír

${ }^{28}$ ABRAHÃO, Maria Helena Menna Barreto. Memória, Narrativas e Pesquisa Autobiográfica. História da Educação. Op.cit. p.80. 
das fontes autobiográficas, no nosso esforço de compreender nosso objeto, fazer o que ela chama de "generalização analítica", foi o que buscamos fazer neste estudo.

A discrição de Teresinha e Tonini para manter o amor e afeto entre ambos sempre existiu. Se assim não tivesse sido, certamente o sentimento entre eles tinha sido de conhecimento público na época e até hoje. Não foi público. Ainda nos resta agora uma indagação definitiva nessa parte deste estudo: o que se deu entre Quinto Tonini e Teresinha Foli foi apenas um sentimento ou se caracterizou um relacionamento de fato? Inferimos a partir de nossa interpretação que foram ambos, tanto sentimento quanto relacionamento. Sentimento na medida em que ambos se gostavam, relacionamento na medida em que se encontravam e correspondiam-se, confidenciavam-se e dividiam alegrias e angústias.

Mas teriam eles mantido relações mais íntimas, como homem e mulher? Para essa pergunta não temos uma resposta definitiva. Pela crítica das narrativas de memória temos como hipótese que não. Ou seja, o sentimento existiu, mas fícou apenas nisso. A própria narrativa de Teresinha que retrata o último encontro entre eles aponta nessa direção. Foi uma despedida entre duas pessoas que nunca assumiram efetivamente o que sentiam um pelo outro, daí o silêncio do último momento, um silêncio que nos diz muito: arrependimento, principalmente. Assim, uma das características principais da escrita autobiográfica é centrada no indivíduo. Sobre essa questão a historiadora Maria Lígia Leite Pereira reflete:

Há pelo menos, cinco elementos fundamentais comuns à
autobiografia: a lenda familiar; o relato de vocação; o exemplo; a
apologia; e a pequena história. Entretanto, as histórias de vida
oferecem condições de enfrentar essas questões, de forma a não
obtermos uma hagiografía, e sim um retrato com nuances,
estabelecido com a colaboração do modelo, e por isso mesmo mais
próximo do indivíduo real: com contradições, limites, defeitos e
qualidades.

Como observa Pereira, existem basicamente cinco modelos ou elementos fundamentais comuns nos escritos autobiográficos. Os relatos de Teresinha são narrativas autobiográficas. Sendo assim, a partir das reflexões de Pereira sobre a existência desses cinco elementos fundamentais que orientam as autobiografias, em qual deles, portanto, se pode encaixar a narrativa autobiográfica de Teresinha Foli?

29 PEREIRA, Lígia Maria Leite. Algumas Reflexões Sobre Histórias de Vida, Biografias e Autobiografias. História Oral. Mariana: Fafich/UFMG, 2000, p.124. 
Seria a da "pequena história", uma história "pequena" porque se desenvolve paralela à história da missão orionita e do catolicismo na região do antigo extremo norte de Goiás, na metade do século passado, atualmente o norte tocantinense.

Consideramos destacar que durante a pesquisa que deu origem a este estudo uma realidade inquietou: a ausência de fontes primárias. Documentos ou mesmo relatos de natureza não orionita que viesse a nos fornecer elementos para outra leitura dos acontecimentos envolvendo os dois missionários, Teresinha Foli e Quinto Tonini. Não tivemos outras versões para aqueles acontecimentos, como por exemplo, relatos escritos de pessoas comuns que conheceram os dois missionários e pudesse oferecer outros subsídios para a construção deste estudo.

Por essa razão, este estudo se preocupou em analisar as versões apresentadas pela própria Teresinha Foli para aqueles acontecimentos, uma versão sob a ótica dela própria. Mas consideramos dizer que o registro autobiográfico da própria missionária analisada a partir de uma leitura crítica e sob um olhar teórico-reflexivo, não diminuiu a criticidade nem a capacidade analítica deste estudo.

Portanto, assim se construíu uma parte da história da missão orionita no extremo norte goiano, uma história "paralela" à "oficial", que narra momentos da missão religiosa na região e que não foi objeto de reflexão neste estudo, mas sim, o amor que existiu entre dois de seus mais importantes missionários. Essa história paralela, problematizada nesta abordagem, a da existência de um sentimento amoroso, uma paixão no seío da congregação orionita, forma o que consideramos ser o outro lado das missões, ou seja, os seus bastidores. 